\title{
Numerical Simulation of Water-Based Alumina Nanofluid in Subchannel Geometry
}

\author{
Mohammad Nazififard, ${ }^{1}$ Mohammadreza Nematollahi, ${ }^{1}$ \\ Khosrow Jafarpur, ${ }^{1}$ and Kune Y. Suh ${ }^{2,3}$ \\ ${ }^{1}$ School of Mechanical Engineering, Shiraz University, Shiraz 71348-51154, Iran \\ ${ }^{2}$ Department of Nuclear Engineering, Seoul National University, Seoul 151-744, Republic of Korea \\ ${ }^{3}$ PHILOSOPHIA Inc., 1 Gwanak Road, Gwanak-gu, Seoul 151-744, Republic of Korea
}

Correspondence should be addressed to Mohammad Nazififard, mnazifi@shirazu.ac.ir

Received 10 July 2012; Revised 7 September 2012; Accepted 11 September 2012

Academic Editor: Iztok Tiselj

Copyright (C) 2012 Mohammad Nazififard et al. This is an open access article distributed under the Creative Commons Attribution License, which permits unrestricted use, distribution, and reproduction in any medium, provided the original work is properly cited.

Turbulent forced convection flow of $\mathrm{Al}_{2} \mathrm{O}_{3}$ /water nanofluid in a single-bare subchannel of a typical pressurized water reactor is numerically analyzed. The single-phase model is adopted to simulate the nanofluid convection of $1 \%$ and $4 \%$ by volume concentration. The renormalization group $\mathrm{k}-\varepsilon$ model is used to simulate turbulence in ANSYS FLUENT 12.1. Results show that the heat transfer increases with nanoparticle volume concentrations in the subchannel geometry. The highest heat transfer rates are detected, for each concentration, corresponding to the highest Reynolds number Re. The maximum heat transfer enhancement at the center of a subchannel formed by heated rods is $\sim 15 \%$ for the particle volume concentration of $4 \%$ corresponding to Re $=$ 80,000 . The friction factor shows a reasonable agreement with the classical correlation used for such normal fluid as the Blasius formula. The result reveals that the $\mathrm{Al}_{2} \mathrm{O}_{3}$ /water pressure drop along the subchannel increases by about $14 \%$ and $98 \%$ for volume concentrations of $1 \%$ and $4 \%$, respectively, given Re compared to the base fluid. Coupled thermohydrodynamic and neutronic investigations are further needed to streamline the nanoparticles and to optimize their concentration.

\section{Introduction}

The heat transfer coefficients in forced convection are governed by thermal conductivity of the fluid as well as by factors representing turbulence and the operating condition. These fluids, including oil, water, and ethylene glycol mixture, are rather poor heat transfer media. Their thermal conductivity plays an important role in the heat transfer between the working fluid and the heated surface.

An innovative way to improve the thermal conductivity of a fluid is to suspend nano-sized particles on the order of $1 \sim 100 \mathrm{~nm}$ with high thermal conductivity in the base fluid with low thermal conductivity.

Generally, the thermal conductivity of the particles, metallic or nonmetallic, is typically an order of magnitude higher than that of the base fluids even at low concentrations resulting in significant increases in heat transfer (Table 1).
Nanofluids thus lend themselves to potential candidates for next generation heat transfer media.

Literature exists [1-16] on the single-phase nanofluids forced convection flow in such various geometries as flat plates, circular tubes, noncircular channels, annuli, and cross flow over circular tubes. The previous results have underscored the enhancement of heat transfer due to the presence of nanoparticles in the fluids. In particular, the heat transfer coefficient increases appear to go beyond the mere thermal conductivity effect and cannot be predicted by such traditional pure fluid correlations as Dittus-Boelter's [4-9]. Pak and Cho [1] experimentally investigated the convective heat transfer behavior of the $\gamma$-alumina $\left(\mathrm{Al}_{2} \mathrm{O}_{3}\right)$ and titanium dioxide $\left(\mathrm{TiO}_{2}\right)$ water-based nanofluids heated in a circular tube with constant heat flux. The Reynolds number Re and Prandtl number Pr varied in the ranges $10^{4}-10^{5}$ and 6.512.3, respectively. They observed that the Nusselt number 
TABle 1: Specific heat capacity and thermal conductivity for different materials [26].

\begin{tabular}{lcc}
\hline Materials & $\begin{array}{c}\text { Specific heat } \\
(\mathrm{kJ} / \mathrm{kg} \mathrm{K})\end{array}$ & $\begin{array}{c}\text { Thermal conductivity } \\
(\mathrm{W} / \mathrm{m} \mathrm{K})\end{array}$ \\
\hline Diamond & 0.509 & 3300 \\
Carbon nanotube & - & 3000 \\
Silver $(\mathrm{Ag})$ & 0.235 & 429 \\
Copper $(\mathrm{Cu})$ & 0.385 & 401 \\
Silicon carbide $(\mathrm{SiC})$ & 1.340 & 350 \\
Titanium carbide $(\mathrm{TiC})$ & 0.711 & 330 \\
Gold $(\mathrm{Au})$ & 0.129 & 317 \\
Aluminum nitride $(\mathrm{AlN})$ & 0.740 & 285 \\
Aluminum $(\mathrm{Al})$ & 0.904 & 237 \\
Silicon $(\mathrm{Si})$ & 0.714 & 148 \\
Graphite & 0.701 & 120 \\
Sodium $(\mathrm{Na})$ & 1.230 & 72.3 \\
Alumina $\left(\mathrm{Al}_{2} \mathrm{O}_{3}\right)$ & 0.773 & 40 \\
Copper oxide $(\mathrm{CuO})$ & 0.551 & 32.9 \\
Titanium dioxide $\left(\mathrm{TiO}_{2}\right)$ & 0.692 & 8.4 \\
Water $($ base fluid) & 4.187 & 0.613 \\
\hline
\end{tabular}

$\mathrm{Nu}$ of the dispersed fluids for fully developed turbulent flow increased with increasing volume concentration as well as Re [1]. They showed that the Darcy friction factors for dilute dispersion fluids used in their study coincided well with the values predicted from Kays' correlation for turbulent flow of a single-phase fluid. Due to the increase in the viscosity of dispersed fluids, there is an additional pumping penalty of approximately $30 \%$ at a volume concentration of $3 \%$ [1].

Experimental investigation of fluid flow in fuel bundle geometry is generally costly, time consuming, and technically complicated, however. In contrast, computational fluid dynamics (CFD) is a nonexpensive method which has seen dramatic growth over the last decade on numerical simulation of nanofluid turbulent convection [5-14, 17-19].

Bianco et al. [5-8] in a series of numerical study analyzed the turbulent forced convection flow of $\mathrm{Al}_{2} \mathrm{O}_{3} /$ water nanofluid in a circular tube subjected to a constant and uniform heat flux at the wall. They showed numerically that the convective heat transfer coefficient for a nanofluid is generally greater than that of the base liquid and that the heat transfer enhancement increases with the particle volume concentration and Re.

Bianco et al. [6] employed single-phase and mixture models with constant thermophysical properties in order to simulate the $\mathrm{Al}_{2} \mathrm{O}_{3} /$ water nanofluid. Their results from the single-phase and mixture models showed that the wall and bulk temperatures were quite similar for $\varphi=1 \%$, while there was a deviation for higher concentrations. They stated that the accuracy of the model could be improved by using a better description of nanofluid thermophysical properties. Bianco et al. [8] also numerically investigated the heat transfer enhancement and entropy generation minimization (EGM) of nanofluids turbulent convection flow in square section tube subjected to constant and uniform wall heat flux. Their EGM analysis showed that, at low Re, the entropy generation on account of the irreversibility of heat transfer dominates, whereas with increasing Re and particles' concentration, the entropy generation due to friction losses becomes more important. They showed an optimal value of Re decreases as particles' concentration increases [8].

Maïga et al. [9] studied numerically the hydrodynamic and thermal behavior of turbulent flow in a tube using the $\mathrm{Al}_{2} \mathrm{O}_{3}$ /water nanofluid under the constant heat flux boundary condition. In their study a new correlation is proposed to calculate the fully developed heat transfer coefficient for the nanofluid considered.

Rostamani et al. [10] simulated the turbulent flow of copper oxide $(\mathrm{CuO})$, alumina $\left(\mathrm{Al}_{2} \mathrm{O}_{3}\right)$, and oxide titanium $\left(\mathrm{TiO}_{2}\right)$ nanofluids with different volume concentrations of nanoparticles flowing through a two-dimensional duct under constant heat flux condition. They emphasized that both $\mathrm{Nu}$ and the heat transfer coefficient of the nanofluid are strongly dependent on nanoparticles and increase with the volume concentration of nanoparticles. Their results showed that the $\mathrm{CuO} /$ water and $\mathrm{TiO}_{2}$ /water nanofluids have the highest and lowest shear stress values, respectively, due to the higher viscosity of copper oxide $(\mathrm{CuO})$ in comparison to other nanofluids.

Behzadmehr et al. [11] numerically studied turbulent forced convection heat transfer in a circular tube with a nanofluid consisting of water and $1 \mathrm{vol} . \%$ of $\mathrm{Cu}$ nano particle. Applying the two-phase mixture model they showed that adding $1 \%$ nanoparticles increases $\mathrm{Nu}$ by more than $15 \%$ while it does not substantially affect the skin friction. They stated that the accuracy of the mixture model could be improved by using suitable effective physical properties for nanofluid instead of volume weighted average of particle and fluid properties, though.

Corcione et al. [12] theoretically analyzed the heat transfer of nanoparticle suspensions in turbulent pipe flow. They assumed nanofluids behave more like single-phase fluids than like conventional solid-liquid mixtures. They showed the existence of an optimal particle loading for either maximum heat transfer at constant driving power or minimum cost of operation at constant heat transfer rate.

Rahimi-Esbo et al. [13] numerically studied the turbulent forced convection jet flow of nanofluid in a converging duct. They showed that by increasing the volume fraction from $0 \%$ to $5 \%$, the average $\mathrm{Nu}$ on the down wall is enhanced by more than $8 \%$.

Ghaffari et al. [14] numerically investigated turbulent mixed convection heat transfer of the $\mathrm{Al}_{2} \mathrm{O}_{3}$ /water nanofluid throughout a horizontal curved tube using a two-phase mixture model. They showed that at the low Grashof number $\mathrm{Gr}$, the turbulent intensity augments with the nanoparticle concentration. While at the higher Gr, where the effect of buoyancy-induced secondary flow becomes important, using higher nanoparticle concentration decreases the flow turbulent intensity across the vertical plan. They showed that the nanoparticle volume fraction enhances Nu. However, its effect on the skin friction coefficient is not significant. Massoudi and Phuoc [15] discussed briefly the constitutive modeling of the stress tensor for nanofluids. 
Mansour et al. [16] investigated the effect due to the uncertainty in the values of the physical properties of the $\mathrm{Al}_{2} \mathrm{O}_{3}$ /water nanofluid on their thermohydrodynamic performance for both laminar and turbulent fully developed forced convections in a tube with a uniform heat flux. They analyzed two types of problems: replacement of a simple fluid by a nanofluid in a given installation and design of an elementary heat transfer installation. They illustrated that the required pumping power for a fixed heat transfer rate and required tube length for fixed mass flow rate and bulk temperature change sizably with the thermophysical properties of the nanofluid.

Palm et al. [20] numerically investigated heat transfer enhancement capabilities of coolants with suspended metallic nanoparticles inside typical radial flow cooling systems. Their results clearly indicate that considerable heat transfer benefits are possible with the use of these fluid/solid particle mixtures.

Eastman et al. [21] reported on interesting properties of nanofluids in their review. They mentioned that although the potential for the use of nanofluids in a wide variety of applications is promising, a key stumbling block seriously hindering the development of the field is that a detailed atomic-level understanding of the mechanisms responsible for the observed property changes remains elusive.

There has recently been an increasing interest in practical application of nanofluid in nuclear reactor technology [17, 18, 22-25]. Considering cooling application of nanofluid it seems that the nanofluids can potentially be applied to power plant cooling and safety systems owing to their enhanced properties such as thermal conductivity for instance. The importance of heat generation and heat transfer processes in nuclear reactors is probably best emphasized by the fact that the rate of heat release and consequently power generation in a given reactor core is limited by thermal rather than by nuclear considerations. There is no limit to the neutron flux level attainable in a reactor core, but the heat generated must be removed well enough.

Kim et al. [22] have worked on application of nanofluid to nuclear reactor. They evaluated the feasibility of nanofluids in nuclear applications by checking on the performance of any water-cooled nuclear system that is heat removal limited. The nanofluids may as well be used in the emergency cooling system, where they could cool down the overheated surfaces more quickly leading to improved power plant safety. Buongiorno and Truong [23] have shown that that circulation of water-based nanofluid in the primary cooling loop of light water reactor (LWR) will improve the heat removal from the core. However, using nanofluids as working fluids has a number of limitations because any change in the reactor core materials affects the criticality and hence the effective neutron multiplication factor. Previous studies of the application of nanofluids to LWR predicted that among nanofluids at low volume concentrations, both the alumina and zirconia nanoparticles are basically transparent to neutrons. They can be used in LWRs since their contribution to coolant activation is minimal [23-25].

Buongiorno et al. [24] assessed the feasibility of using nanofluids to enhance the in-vessel retention capability in light water reactors. They assessed the benefits of critical heat flux enhancement by nanofluids for decay heat power removal. Their analysis indicates that the use of nanofluid can increase the in-vessel retention capability of nuclear reactors by as much as $40 \%$ [24].

Hadad et al. [25] have recently reported that $\mathrm{Al}_{2} \mathrm{O}_{3}$ shows the lowest rate of multiplication factor dropoff in comparison to aluminum, copper oxide, copper, and zirconia nanoparticles with different concentrations in nanofluids. As compared with other nanomaterials such as carbon nanotubes, $\mathrm{Al}_{2} \mathrm{O}_{3}$ nanoparticle is cheaper and has been used extensively in cooling application of nanofluids. Recently, Nazififard et al. [17] numerically evaluated characteristics of $\mathrm{Al}_{2} \mathrm{O}_{3}$ /water nanofluids for prospective application to watercooled research reactors. Their results showed that the heat transfer is enhanced by about $4 \%$ using nanofluid of $1 \%$ by volume in comparison to the base fluid and that the pressure drop of nanofluids is only about $3 \%$ higher than that of the base fluid [17]. They also showed that injection of nanofluid into the core could help circumvent a runaway nuclear reaction even under normal operation and increase the safety margins. Nazififard et al. [18] numerically studied the waterbased nanofluid coolant for a typical small modular reactor as well.

The scope of the present paper is to make a further contribution to nanofluids turbulent convection in subchannel geometry by numerically investigating developing turbulent forced convection flow of $\mathrm{Al}_{2} \mathrm{O}_{3}$ /water nanofluid in a subchannel.

\section{CFD Methodology}

2.1. Mathematical Modeling. The fluid flow in the water cooled reactor is parallel to the fuel rod bundle, and the unit channel is called subchannel. A single subchannel is modeled using the flow symmetry which has been modeled extensively before [18, 19, 27-29]. Steady-state Reynolds-averaged Navier-Stokes, mass, energy, and turbulence equations were discretized and solved using FLUENT 12.1. The continuity, momentum, and energy equations are as follows [29]:

$$
\begin{gathered}
\frac{\partial\left\langle u_{i}\right\rangle}{\partial x_{i}}=0 \\
\frac{\partial\left\langle u_{i}\right\rangle\left\langle u_{j}\right\rangle}{\partial x_{j}}=-\frac{\partial\langle P\rangle}{\partial x_{i}} \\
+\frac{\partial}{\partial x_{j}}\left[\mu\left(\frac{\partial\left\langle u_{i}\right\rangle}{\partial x_{j}}+\frac{\partial\left\langle u_{j}\right\rangle}{\partial x_{i}}\right)-\rho\left\langle\dot{u}_{i} u_{j}\right\rangle\right]+\rho g_{i}, \\
\frac{\partial}{\partial x_{i}}\left(\left\langle u_{i}\right\rangle(\rho E+P)\right)=\frac{\partial}{\partial x_{i}}\left(k_{\mathrm{eff}} \frac{\partial T}{\partial x_{i}}+u_{j}\left(\tau_{i j}\right)_{\mathrm{eff}}\right) .
\end{gathered}
$$

The renormalization group (RNG) $k-\varepsilon$ model is used to simulate turbulence in ANSYS FLUENT [28] proposed by Yakhot et al. [30] to renormalize the Navier-Stokes equations and to account for the effect of smaller scales of motion. The RNG $k-\varepsilon$ model is an alternative to the standard $k-\varepsilon$ model. 
It generally offers little improvement over the standard $k-\varepsilon$ model, though. Standard wall treatment was adopted near the wall for the momentum and energy equations [28].

2.2. Computational Domain and Meshes. The problem under consideration consists of steady, forced turbulent convection flows and heat transfer of a nanofluid flowing inside a subchannel of a typical pressurized water reactor (PWR). The computational model geometry and the grid were generated using GAMBIT, the preprocessing module for the FLUENT software [28]. The computational domain boundaries and meshes are shown in Figure 1. The CFD domain consists of a subchannel with length $L$ of 605 $\mathrm{mm}$. The fuel rod diameter $D$ is $9.5 \mathrm{~mm}$, and the pitch-todiameter ratio $P / D$ is 1.32 . The hydraulic diameter $D_{h}$ of the subchannel is $11.8 \mathrm{~mm}$. The channel has appropriate length in order to obtain fully developed velocity and temperature profiles at the outlet. The condition of the constant wall heat flux is considered in this study.

2.3. Mesh Generation Sensitivity and Turbulence Model. The accuracy of finite volume method is directly related to the quality of the discretization used. In this study, structured hexahedral meshes are used which are known to provide higher accuracy and reduce the CFD computational effort (Figure 1) [27]. A comprehensive mesh sensitivity study was done to check on the influence of the mesh resolution on the results and to minimize numerical influences introduced by the size of meshes and their distributions. For mesh sensitivity analysis, four meshes of differing size were used ranging from 0.32 to 0.65 million for the single subchannel (Table 2). Note from the cross-sectional view of meshes in Figure 1 that mesh refinement was improved in each mesh refinement process. The mesh refinement ratio (MRR) is defined as the ratio between consecutive meshes of mesh refinement. Table 2 shows that, for the considered subchannel, the mesh M4 appears to be satisfactory to ensure the accuracy of numerical results as well as their independency with respect to the number of nodes used.

2.4. Boundary Conditions. The fluid enters with uniform temperature of $T_{0}=293 \mathrm{~K}$ and velocity $V_{0}$ profiles at the subchannel inlet. Different inlet uniform velocities are applied which are listed in Table 3. In order to validate the CFD model Re and thermal boundary condition were chosen to match Re of the available correlations [1,9]. At the outlet of the computational model a relative average pressure equaling zero was defined. The surfaces of the walls were assumed hydraulically smooth. A constant heat flux $q=50 \mathrm{KW} / \mathrm{m}^{2}$ is specified for the wall (rod surface). A similar approach with Bianco et al. [5-7] has been chosen to calculate the $\operatorname{Re}\left(\operatorname{Re}=\left(\rho \cdot v \cdot D_{h}\right) / \mu\right)$ based on thermophysical properties of $\mathrm{Al}_{2} \mathrm{O}_{3}$ /water nanofluid at different volume fractions of $1 \%$ and $4 \%$ at $T_{0}=293 \mathrm{~K}$.

2.5. Numerical Method. The modeled cases were solved using ANSYS FLUENT software version 12.1 [28]. A segregated, implicit solver option was used to solve the governing equations. The first order upwind discrimination scheme was employed for the terms in energy, momentum, and turbulence parameters. A standard pressure interpolation scheme and SIMPLE pressure velocity coupling were implemented. A residual root-mean-square (RMS) target value of $10^{-5}\left(10^{-8}\right.$ for energy equation) was defined for the CFD simulations.

The simulations are performed on the desktop computer with Intel Core I5 $2.4 \mathrm{GHz}$ with $4 \mathrm{~GB}$ installed RAM. The typical CPU time for each modeling was about 25,200 s.

2.6. Thermophysical Properties of the Nanofluids. The determination of nanofluid thermophysical properties is an increasingly important area in nanofluid cooling applications. A considerable amount of literature has been accumulated on the basic nanofluid thermophysical properties over the past few years but at present there is no agreement within the nanofluid community about description of thermophysical properties $[15,21,26]$. The available experimental data are rather controversial, and there is no systematic study on thermophysical properties of nanofluids.

The single-phase approach is chosen to calculate the thermophysical properties of nanofluids as it is widely used in the literature $[5-9,17,18]$. In this model the homogenous mixture is assumed prior to solving the governing equations of continuity, momentum, and energy for the single phase fluid flow that the presence of nanoparticles is realized by modifying physical properties of the mixture fluid. It is assumed that there is no velocity difference between fluids and the particles, and the fluids and the particles are in thermal equilibrium [5-8]. This assumption implies that all the convective heat transfer correlations available in the literature for single-phase flows can be extended to nanoparticle suspensions, providing that the thermophysical properties appearing in them are the nanofluid effective properties calculated at the reference temperature $[11,12]$.

Note that most nanofluids used in practical applications usually comprise the oxide particles finer than $40 \mathrm{~nm}$ [9]. In the current CFD study the considered nanofluid is a mixture of water and particles of $\mathrm{Al}_{2} \mathrm{O}_{3} 38 \mathrm{~nm}$ in mean particle diameter. Equations (2)-(5) were used to compute the thermophysical properties of the alumina nanofluids for the CFD simulation [5-9, 17, 18]. The thermophysical properties of the $\mathrm{Al}_{2} \mathrm{O}_{3}$ nanoparticle and water-based nanofluid are presented at temperature $293 \mathrm{~K}$ in Tables 4 and 5 , respectively,

$$
\begin{aligned}
\rho_{\mathrm{nf}} & =(1-\varphi) \rho_{\mathrm{bf}}+\varphi \rho_{p} \\
\left(\rho c_{\mathrm{p}}\right)_{\mathrm{nf}} & =(1-\varphi)\left(\rho c_{p}\right)_{\mathrm{bf}}+\varphi\left(\rho c_{p}\right)_{p} \\
\mu_{\mathrm{nf}} & =\left(123 \varphi^{2}+7.3 \varphi+1\right) \mu_{b f} \\
k_{\mathrm{nf}} & =\left(4.97 \varphi^{2}+2.72 \varphi+1\right) k_{b f}
\end{aligned}
$$

In the absence of experimental data, classical formula for the two-phase mixture is used to calculate the nanofluid density which is a constant value independent of temperature $[5-9,17,18]$. 

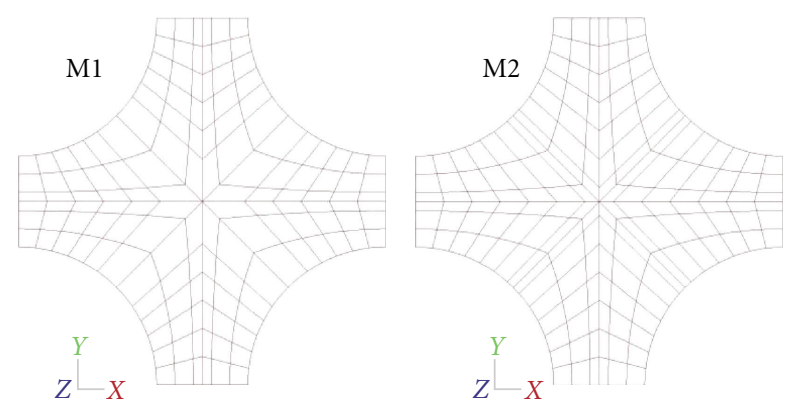
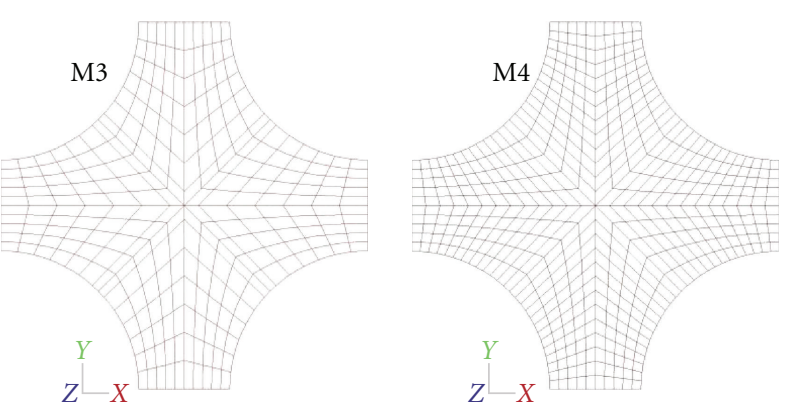

(a)

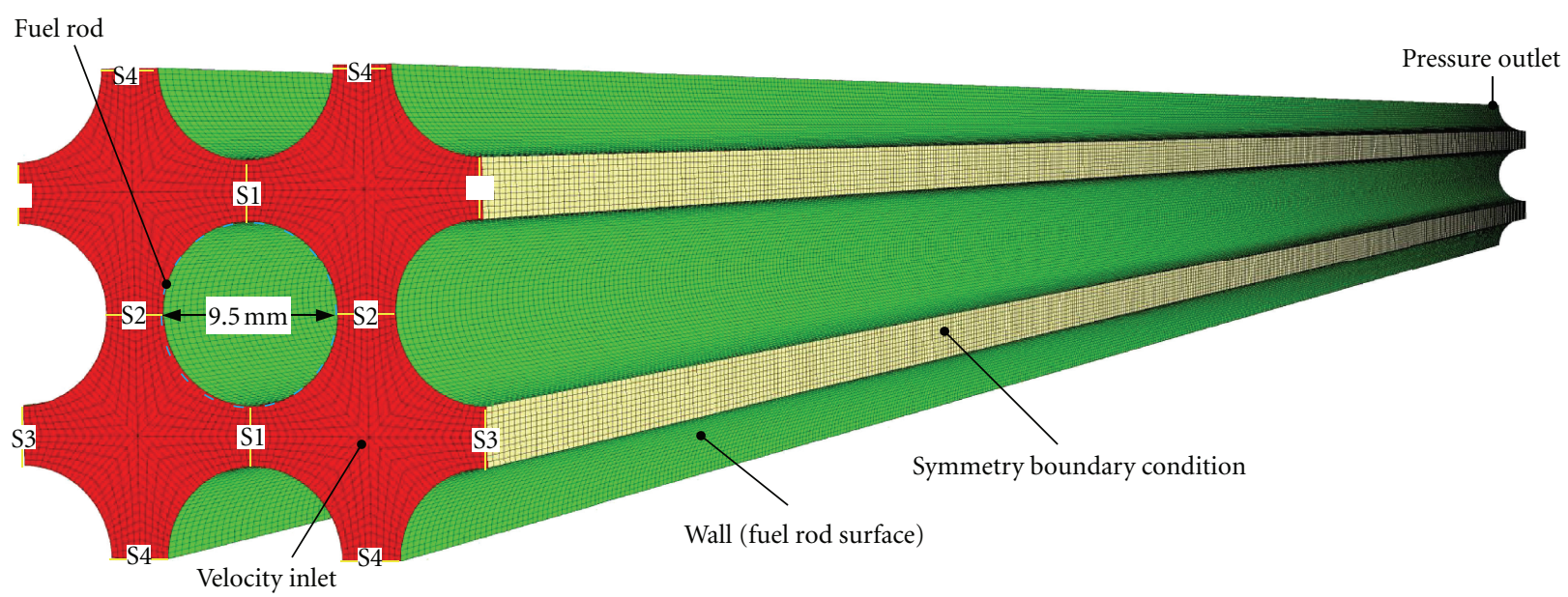

(b)

FIgURe 1: Computational domain and meshes.

TABLE 2: MRR and differences in terms of $\mathrm{Nu}$ among the different tested meshes.

\begin{tabular}{lcc}
\hline Step & MRR & $\left(\Delta \mathrm{Nu}_{\mathrm{av}}\right)$ \\
\hline $2 \rightarrow 1$ & 1.16 & $6.26 \%$ \\
$3 \rightarrow 2$ & 1.66 & $1.53 \%$ \\
$4 \rightarrow 3$ & 2.46 & $0.01 \%$ \\
\hline
\end{tabular}

TABLE 3: Inlet velocities and Re.

\begin{tabular}{lccc}
\hline Re & Water & $\varphi=1 \%$ & $\varphi=4 \%$ \\
\hline $20 \times 10^{3}$ & 1.694 & 1.787 & 2.262 \\
$40 \times 10^{3}$ & 3.389 & 3.574 & 4.525 \\
$60 \times 10^{3}$ & 5.083 & 5.362 & 6.788 \\
$80 \times 10^{3}$ & 6.778 & 7.149 & 9.051 \\
\hline
\end{tabular}

TABLE 4: $\mathrm{Al}_{2} \mathrm{O}_{3}$ nanoparticle at temperature of $293 \mathrm{~K}$ [5-9].

\begin{tabular}{lccc}
\hline & $\rho\left(\mathrm{kg} / \mathrm{m}^{3}\right)$ & $C_{p}(\mathrm{~J} / \mathrm{kg} \mathrm{K})$ & $K(\mathrm{~W} / \mathrm{m} \mathrm{K})$ \\
\hline Alumina $\left(\mathrm{Al}_{2} \mathrm{O}_{3}\right)$ & 3880 & 773 & 36 \\
\hline
\end{tabular}

Similarly, a couple of expressions are proposed for determining the nanofluids specific heat $[1,5-9,17,18]$. Equation (3) is theoretically more consistent since the specific heat is a mass-specific quantity whose effect depends on the density of the components of a mixture [4-6].
TABle 5: Properties of water based $\mathrm{Al}_{2} \mathrm{O}_{3}$ /water nanofluid at different volume fractions equaling $1 \%$ and $4 \%$ at $T_{0}=293 \mathrm{~K}$.

\begin{tabular}{lcccc}
\hline$\varphi$ & $\rho\left(\mathrm{kg} / \mathrm{m}^{3}\right)$ & $c_{p}(\mathrm{~J} / \mathrm{kg} \mathrm{K})$ & $\mu(\mathrm{Pa} \cdot \mathrm{s})$ & $k(\mathrm{~W} / \mathrm{m} \mathrm{K})$ \\
\hline $0 \%$ & 998.2 & 4182 & $998 e^{-6}$ & 0.597 \\
$1 \%$ & 1027 & 4053 & $1083 e^{-6}$ & 0.614 \\
$4 \%$ & 1113 & 3707 & $1486 e^{-6}$ & 0.667 \\
\hline
\end{tabular}

The nanofluid viscosity is an important parameter for practical applications since it directly affects the pressure drop in forced convection. Equation (4) is purely experimental and turns out to be more apt than the classical models, such as Einstein or Brinkman, which drastically underestimate the nanofluid viscosity [5-8]. Equation (5) is based on a classical model, nonetheless yields good estimation of the thermal conductivity in the present case [59].

\section{Results}

Results are reported in terms of the average $\mathrm{Nu}$, convective heat transfer coefficient, and pressure drop as a function of Re ranging from $20 \times 10^{3}$ to $80 \times 10^{3}$, and particle volume concentrations of $0 \%, 1 \%$, and $4 \%$. Results were obtained by the single-phase approach with the constant heat flux $q=50 \mathrm{~K} \mathrm{~W} / \mathrm{m}^{2}$ on the wall. In all cases the particles size 
was considered equal to $38 \mathrm{~nm}$. Results were validated by comparing the obtained ANSYS FLUENT results against the Dittus-Boelter correlation [31] for the case of pure water

$$
\begin{gathered}
\mathrm{Nu}=0.024 \operatorname{Re}^{0.8} \operatorname{Pr}^{0.4} \\
0.5<\operatorname{Pr}<120, \\
6.0 \times 10^{3}<\operatorname{Re}<1.0 \times 10^{7} .
\end{gathered}
$$

For the $\mathrm{Al}_{2} \mathrm{O}_{3}$ /water nanofluid the validation has been performed by the available correlations considering a fully developed flow in terms of the average $\mathrm{Nu}$ and friction coefficients for smooth pipe. $\mathrm{Nu}$ is compared with correlations suggested by Pak and Cho [1] (7) and Maïga et al. [9] (8) both of which have been widely used in the literature:

$$
\begin{gathered}
\mathrm{Nu}=0.021 \operatorname{Re}^{0.8} \operatorname{Pr}^{0.5} \\
10^{4} \leq \operatorname{Re} \leq 10^{5}, \\
6.5 \leq \operatorname{Pr} \leq 12.3, \\
0<\varphi<3 \%, \\
\mathrm{Nu}=0.085 \operatorname{Re}^{0.71} \operatorname{Pr}^{0.35} \\
10^{4} \leq \operatorname{Re} \leq 5 \times 10^{5}, \\
6.6 \leq \operatorname{Pr} \leq 13.9, \quad 0<\varphi<10 \% .
\end{gathered}
$$

Note that the above correlations calculate the heat transfer coefficient in a tube using the $\mathrm{Al}_{2} \mathrm{O}_{3}$ /water nanofluid under the constant heat flux boundary condition.

3.1. Velocity and Turbulence. Figure 2 shows the development of the velocity magnitude along the subchannel centerline for $\varphi=4 \%$. The results suggest the existence of a fully developed region for $z=25 \times D_{h}$ and $\mathrm{Re}=$ $20 \times 10^{3}$, whereas the developing length $z=30 \times D_{h}$ for $\operatorname{Re}=80 \times 10^{3}$. It is clear that the fully developed values of the nondimensional centerline velocity $\left(V / V_{\text {in }}\right)$ decrease as $\operatorname{Re}$ increases because the corresponding velocity profiles become more uniform as Re increases. It is noted that, downstream of the channel inlet, the boundary layer growth pushes the fluid towards the centerline region, causing an increase of the centerline velocity in accordance with $[1,11]$. This may attribute to due to the fact that the corresponding velocity profiles become more uniform as Re increases.

Figure 3 shows the profiles of velocity magnitude along the central line of channel for $\operatorname{Re}=80 \times 10^{3}$ and $\varphi=0 \%, 1 \%$ and $4 \%$, respectively. The numerical results show that, if the current assumptions are used to model the fluid properties, the presence of the nanoparticles does not affect the velocity profile.

The contour of velocity $(\mathrm{m} / \mathrm{s})$ and turbulent kinetic energy $\left(\mathrm{m}^{2} / \mathrm{s}^{2}\right)$ at the outlet for pure water at $\mathrm{Re}=20 \times 10^{3}$ at outlet are depicted in Figure 4.

The stability of the suspensions in nanofluids is the single most critical issue for enhancing heat transfer. Nanoparticles

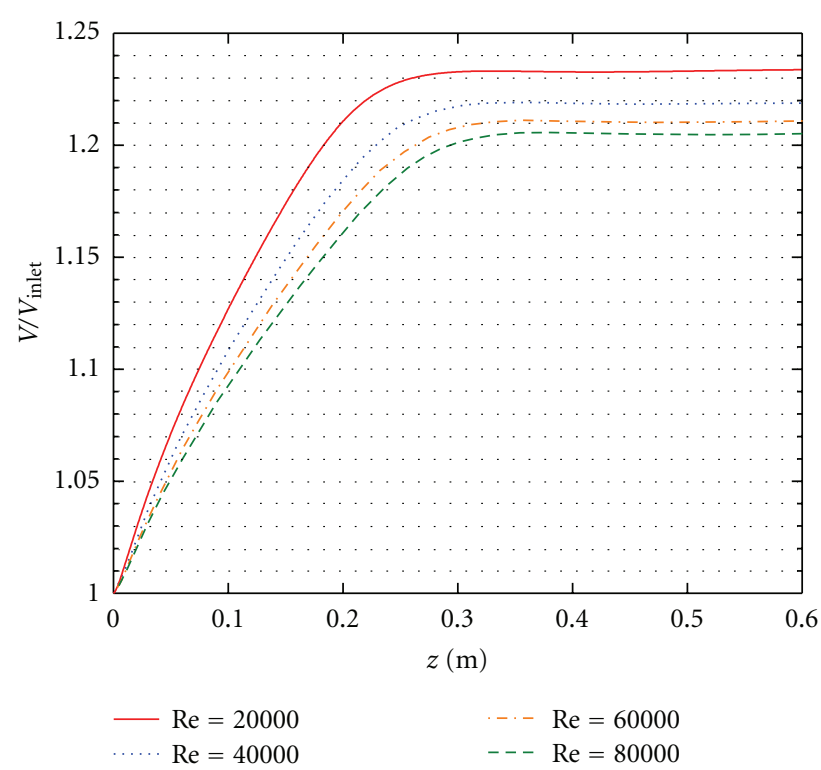

Figure 2: Normalized velocity distributions along the centerline channel for $\mathrm{Al}_{2} \mathrm{O}_{3} /$ water 4 vol. \% at different Re.

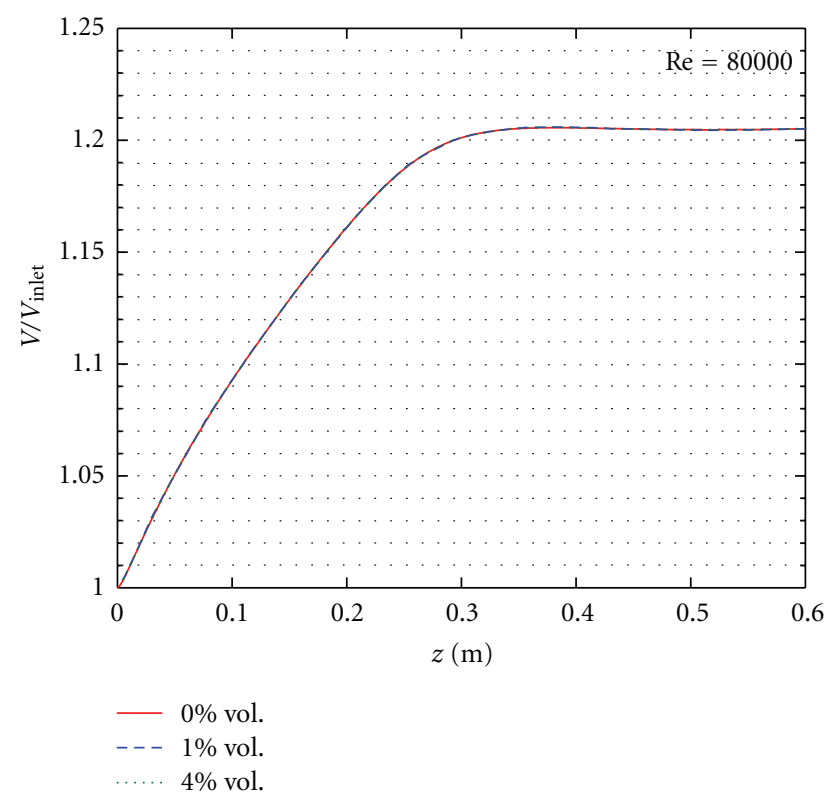

FIGURE 3: Normalized velocity distribution along the centerline of channel for $\operatorname{Re}=80 \times 10^{3}$.

generally tend to settle down and deposit on the wall. The nanoparticle clogging is another problem which can change the thermo and hydrodynamic characteristics of the coolant.

An important flow parameter affecting the homogeneity and stability of nanofluid in forced turbulent flow is the level of flow turbulence intensity. The turbulence intensity, TI, often referred to as turbulence level is defined as the ratio of the root-mean-square of the velocity fluctuations, $\dot{u}$, to the mean flow velocity $U$ [28]. 


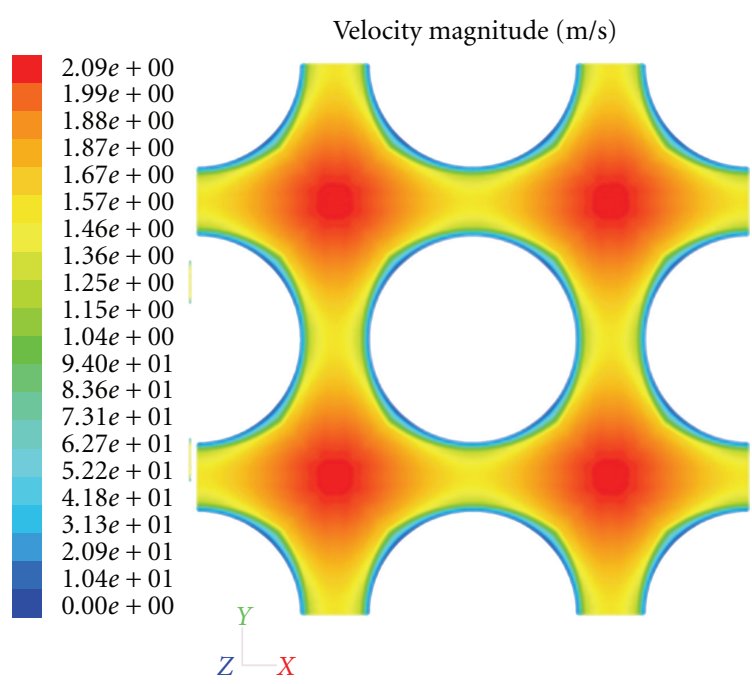

(a)

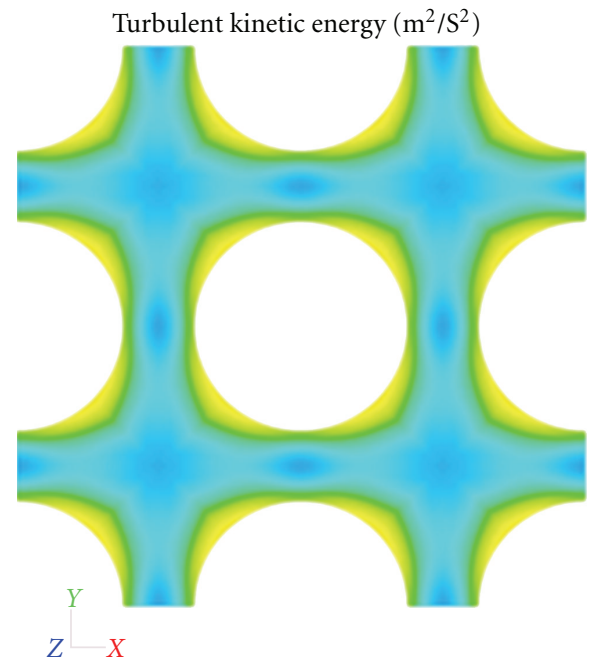

(b)

Figure 4: Contour of velocity and turbulent kinetic energy at the outlet for pure water at $\operatorname{Re}=20 \times 10^{3}$.

Figure 5 displays the turbulence intensity at $\mathrm{Re}=80 \times 10^{3}$ for nanofluid $\varphi=4 \%$ at the pressure outlet. The turbulent intensities are high at the walls and levels down away from the walls. Observe that there are regions of relatively high axial turbulence intensity on the rods close to rod gap. These saddle points are located on both sides at about $45^{\circ}$ from the gap between the rods. Behzadmehr et al. [11] showed that the particles can absorb the velocity fluctuation energy and reduce the turbulent kinetic energy.

3.2. Temperature Distribution. Contours of temperature at the outlet for base fluid and nanofluids are shown in Figure 6 . Observe that the inclusion of nanoparticles has a beneficial effect on the wall and bulk temperatures of the nanofluid compared to base fluid.

Figure 7 illustrates the coolant temperature distribution along the centerline of the subchannel for different volume concentration of nanofluids. Note that there is a steady increase in the coolant temperature distribution along the channel for all the cases. As the coolant moves along the channel, it absorbs heat. Note that the bulk temperature for $\varphi=1 \%$ and $\varphi=4 \%$ is lower than the case of base fluid. The FLUENT results point to the temperature decrease due to the presence of the particles considering the constant heat flux at the wall (rod surfaces) for all cases.

3.3. Heat Transfer. Heat transfer calculations were made for different volume concentration of nanofluid by applying a constant temperature to the inlet of the channel and a constant uniform heat flux to rod walls along the subchannel. In this study the local and average heat transfer coefficients are defined as follows:

$$
\begin{gathered}
h(z)=\frac{q}{T(z)_{W}-T(z)_{b}}, \\
h_{a v}=\frac{1}{L} \int_{0}^{L} h(z) d z .
\end{gathered}
$$

The average heat transfer coefficient for all the concentrations and considered Re is reported in Figure 8. Notice the useful contribution to the heat transfer provided by the inclusion of nanoparticles in comparison to the case with just the base fluid. Also note that heat transfer increases with the particles volume concentration and Re. The highest heat transfer rates are identified, for each concentration, at the highest Re. The observed increase in heat transfer coefficient could be attributed to improved thermophysical properties of the mixture with respect to the base fluid. Thus, a nanofluid with higher thermal conductivity increases the heat transfer along the channel. Moreover, the term $\rho$. $c_{p}$ increases; therefore, more energy is required to increase the bulk temperature with respect to the case of the base water $[5-9,17,18]$. However, the difference between the wall and bulk temperatures decreases with respect to the case of the base fluid provoking the increase of the heat transfer coefficient. Previous studies [1-9] have yet shown that the increase in heat transfer is generally higher than that of the thermophysical properties. These explanations are not convincing enough to explain the increase in the heat transfer due to a nanofluid.

A Nu study was carried out by taking averages over the wall surface in the region. The results are given in Table 6 . The average $\mathrm{Nu}$ is defined as follows:

$$
\mathrm{Nu}_{a v}=\frac{h_{a v} \cdot D}{k_{0}}
$$

Figure 9 shows the average $\mathrm{Nu}$ for all the concentrations and Re compared against the experimental and numerical correlations available in the literature $[1,9]$. The ANSYS FLUENT results are compared against the experimental correlations proposed by Pak and Cho [1] and the numerical correlation proposed by Maïga et al. [9].

Bianco et al. [5, 6] reported that the Maïga et al. [9] correlation overestimates the values provided by Pak and Cho [1] by about $20 \%$ which is clearly shown in Figure 10 . 

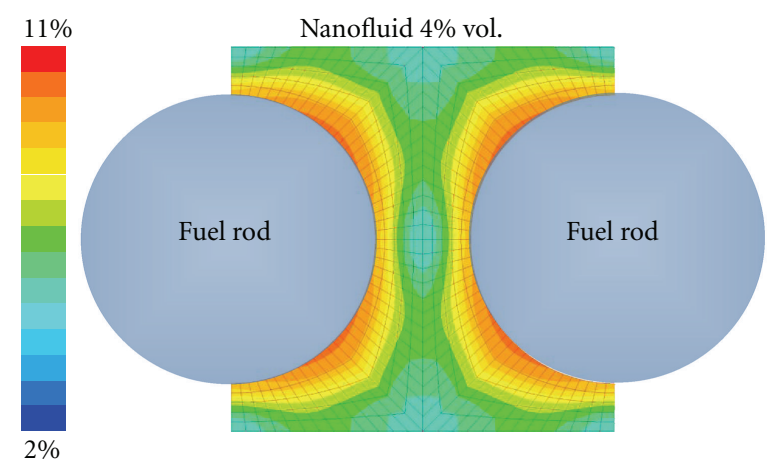

(a)

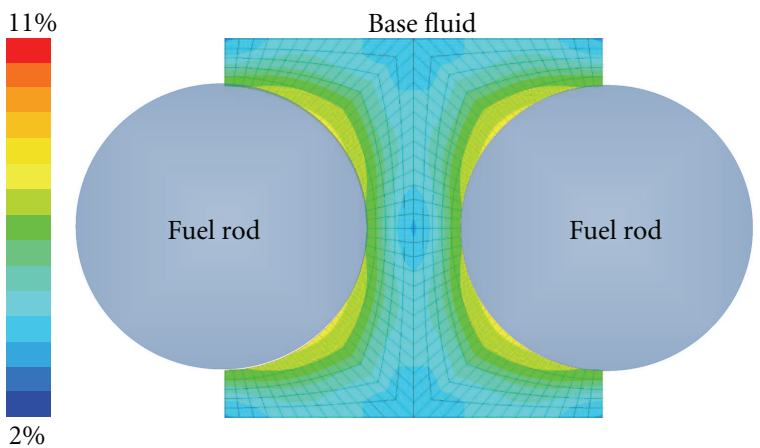

(b)

FIgURE 5: Turbulent intensity at the channel at $\mathrm{Re}=80 \times 10^{3}$.

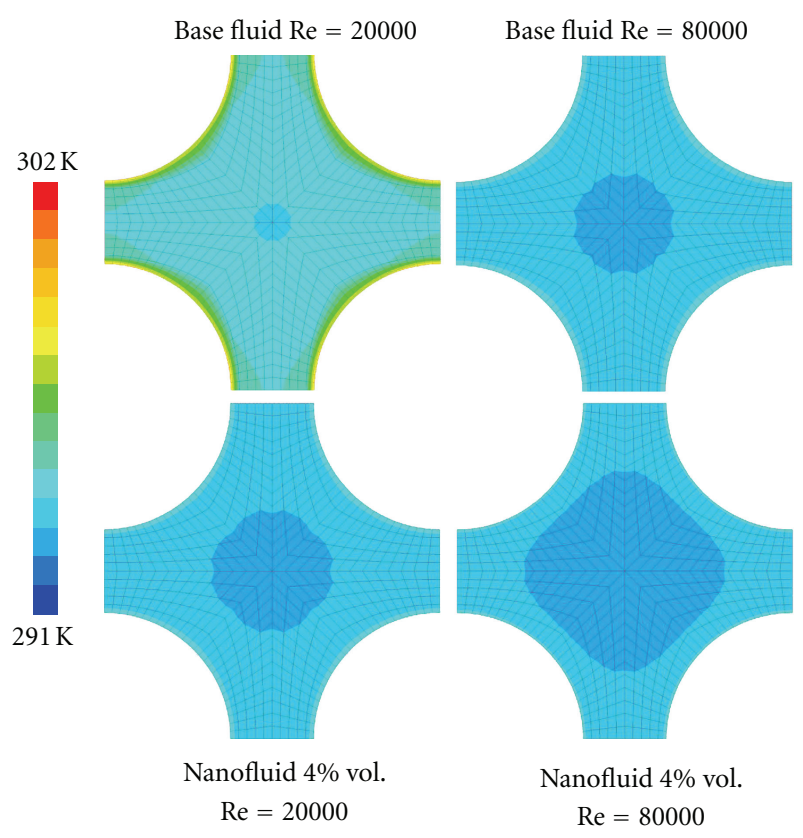

Figure 6: Temperature profile at the outlet for base fluid and nanofluid and $\operatorname{Re}=20 \times 10^{3}$ and $80 \times 10^{3}$.

However, this overestimation can be considered acceptable, as reported also by Buongiorno [4]. The Pak and Cho [1] correlation concurs with the FLUENT result at $\mathrm{Re}=20 \times 10^{3}$, while at higher $\operatorname{Re}=80 \times 10^{3}$ the Maïga et al. [9] correlation agrees with the FLUENT result.

3.4. Pressure Drop. The pressure drop of the coolant in the heated channel is one of the central parameters determining the efficiency of nanofluids application. The pressure drop and coolant pumping power are closely related. The pressure distribution in the subchannel for different volume concentrations of nanofluid at different Re is shown in Figure 11. It is clear that there is a linear decrease in the pressure drop along the channel for all the cases. Figure 11 clearly shows that the pressure drop of nanofluids increases with the increasing volume concentrations. This result may be

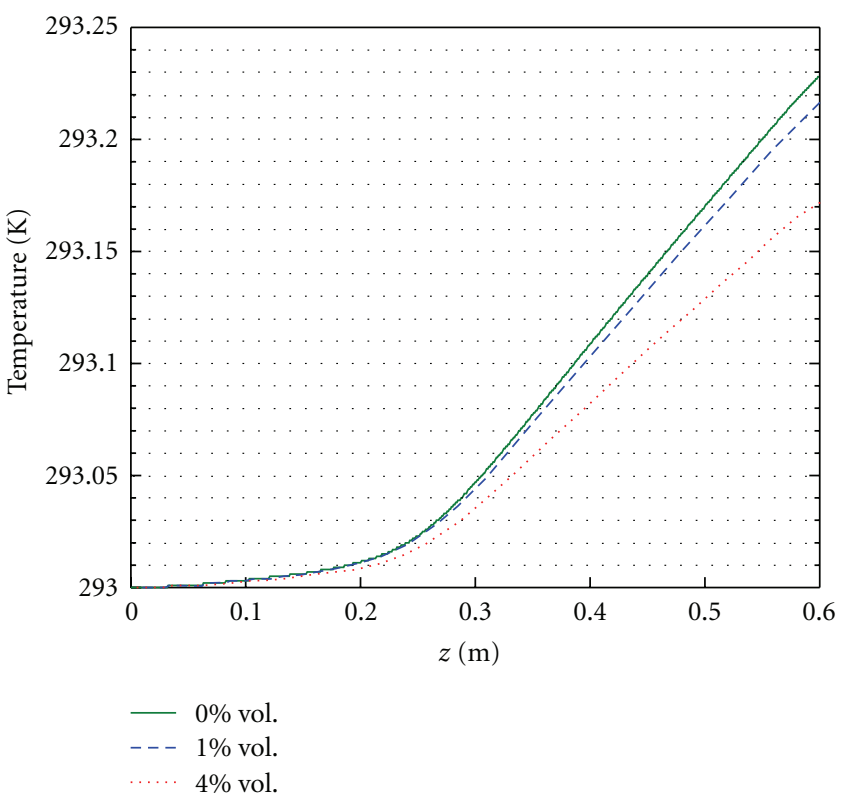

FIGURE 7: Coolant temperature distribution along centerline of channel for different volume concentration of nanofluids for $\mathrm{Re}=$ $80 \times 10^{3}$.

explained by the fact that the density and viscosity are the main thermophysical parameters which could influence the coolant pressure drop and coolants.

Several studies [1-9] have revealed that that the pressure drop of the nanofluids fairly matches with the values predicted by the conventional correlations of base fluid for both laminar and turbulent flows. Hence, the conventional fraction factor correlation can be used for the pressure drop prediction. The experimental study by Xuan and Li [3] implied that the friction factor correlation for the singlephase flow (base fluid) can be extended to the dilute nanofluids. Figure 12 shows the pressure drop along the channel compared with pressure drop estimated by Blasius formula.

It assumed that the wall of the channel is smooth and the friction factors may as well be determined for turbulent 


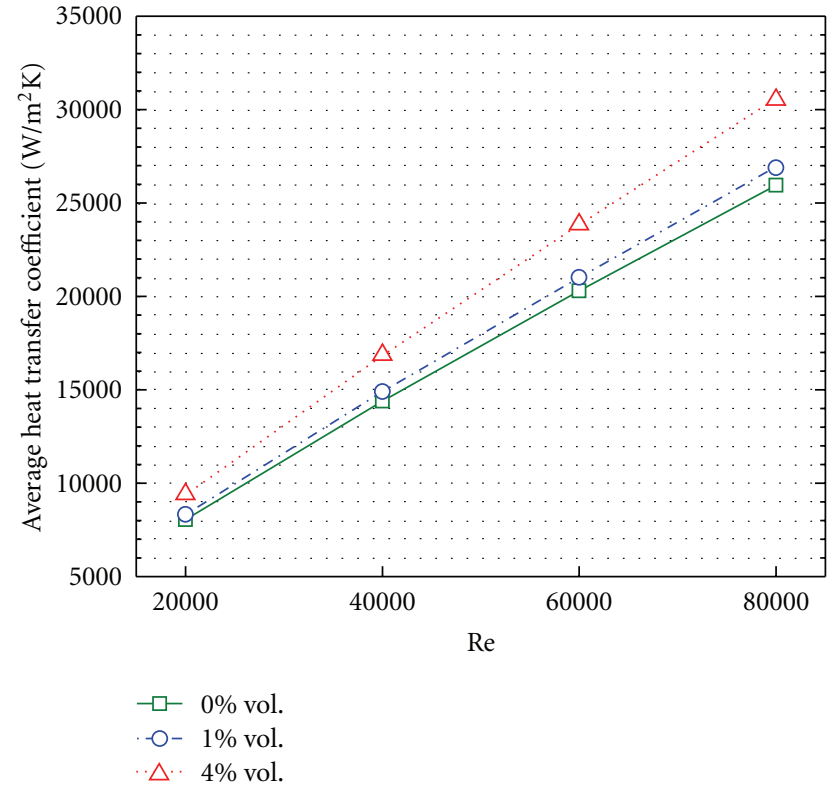

Figure 8: Average heat transfer coefficient for all concentrations and Re.

Table 6: Average Nu.

\begin{tabular}{lccc}
\hline Re & & $\mathrm{Nu}_{\mathrm{av}}$ & \\
\hline 20,000 & $\varphi=0 \%$ & $\varphi=1 \%$ & $\varphi=4 \%$ \\
40,000 & 158.9 & 159.9 & 166.4 \\
60,000 & 284.4 & 286.2 & 298.5 \\
80,000 & 401.2 & 404.0 & 421.9 \\
\hline
\end{tabular}

flow as in a smooth pipe pursuant to the Moody diagram or alternative correlation. For $2300<\operatorname{Re}<100 \times 10^{3}$, the singlephase flow turbulent friction factor for a smooth tube may be estimated by the Blasius formula as follows:

$$
f=\frac{0.3164}{\operatorname{Re}^{0.25}}
$$

The pressure loss due to the flow friction may be calculated as follows:

$$
\Delta P=f\left(\frac{L}{2 D_{h}}\right) \rho v^{2} .
$$

Figure 13 shows the performances of the Blasius correlations to predict the pressure drop of nanofluid. The Blasius correlation underestimates the result, but the differences are less than $3 \%$ at $\operatorname{Re}<40 \times 10^{3}$. The maximum difference is found for $\operatorname{Re}=80 \times 10^{3}$, which is about $5 \%$.

For easy understanding of the pressure drop of the nanofluid, the differences in pressure drop along the subchannel for nanofluid are compared with base fluid which is defined as follows:

$$
d P=\left(\frac{\Delta P_{\mathrm{nf}}-\Delta P_{\mathrm{bf}}}{\Delta P_{\mathrm{bf}}}\right) \times 100(\%) .
$$

The result reveals that the $\mathrm{Al}_{2} \mathrm{O}_{3}$ /water pressure drop increases by about $14 \%$ and $98 \%$ for $\varphi=1 \%$ and $\varphi=4 \%$ of, respectively, given Re.

\section{Conclusions}

Numerical simulation has been presented on heat transfer characteristics and pressure drop of $\mathrm{Al}_{2} \mathrm{O}_{3}$ /water nanofluid in subchannel geometry under steady state turbulent flow. The homogenous fluid assumptions with modified thermophysical properties were taken into account in order to simulate the $\mathrm{Al}_{2} \mathrm{O}_{3}$ /water nanofluid. The CFD predictions were compared against the available experimental data and literature correlations. The following conclusions can be drawn from the present study.

(i) CFD predictions were shown to reproduce the enhancement in heat transfer, with respect to the base fluid, known to characterize nanofluids. Convective heat transfer and friction pressure drop were correctly predicted to increase with the $\mathrm{Al}_{2} \mathrm{O}_{3}$ nanoparticle concentration.

(ii) The Pak and Cho [1] correlation concurs with the FLUENT result at $\operatorname{Re}=20 \times 10^{3}$, while the Maïga et al. [9] correlation agrees with the FLUENT result at $\operatorname{Re}=80 \times 10^{3}$.

(iii) The Blasius correlation underestimates the FLUENT result, but the differences are less than $3 \%$ at $\operatorname{Re}<40$ $\times 10^{3}$. The maximum difference is found for $\mathrm{Re}=80$ $\times 10^{3}$, which is about $5 \%$.

(iv) The result reveals that the pressure drop of nanofluid along subchannel increases by about $14 \%$ and $98 \%$ for $\varphi=1 \%$ and $\varphi=4 \%$ of, respectively, given Recompared to the base fluid.

A complete understanding of heat transfer performance of the nanofluids is prerequisite to their practical application to a commercial nuclear reactor. It is recommended that further research be undertaken to analyze nanofluids for apt nanoparticle and its optimum concentration in the base fluid. Coupled thermohydrodynamic and neutronic investigations are further needed to streamline the nanoparticles and to optimize their concentration.

\section{Nomenclature}

$c_{p}:$ Specific heat, $\mathrm{J} / \mathrm{kg} \mathrm{K}$

$D$ : Diameter, $\mathrm{m}$

$D_{h}$ : Equivalent hydraulic diameter, $\mathrm{m}$

E: Empirical constant in turbulence model (9.793)

$f$ : Friction factor

g: Gravity acceleration, $\mathrm{m} / \mathrm{s}^{2}$

$h$ : Heat transfer coefficient, $\mathrm{W} / \mathrm{m}^{2} \mathrm{~K}$

$k$ : Thermal conductivity, $\mathrm{W} / \mathrm{m} \mathrm{K}$

$\mathrm{Nu}$ : Nusselt number

$P: \quad$ Mean pressure, $\mathrm{Pa}$

Pr: Prandtl number 


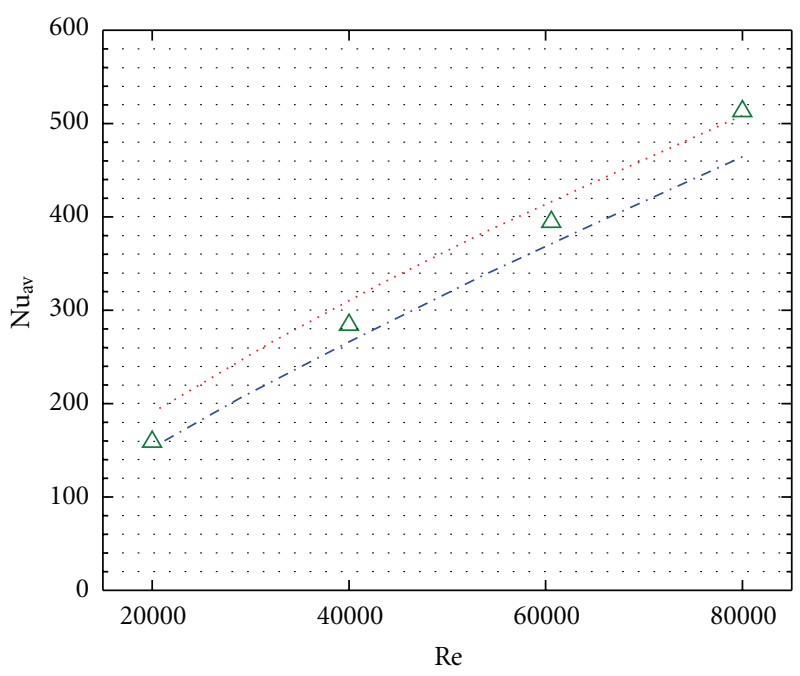

$\mathrm{Al}_{2} \mathrm{O}_{3} /$ water $4 \%$ vol.

-. - Nu (Pak and Cho) [1]

$\mathrm{Nu}$ (Maïga et al.) [9]

$\triangle \mathrm{Nu}$ (ANSYS FLUENT)

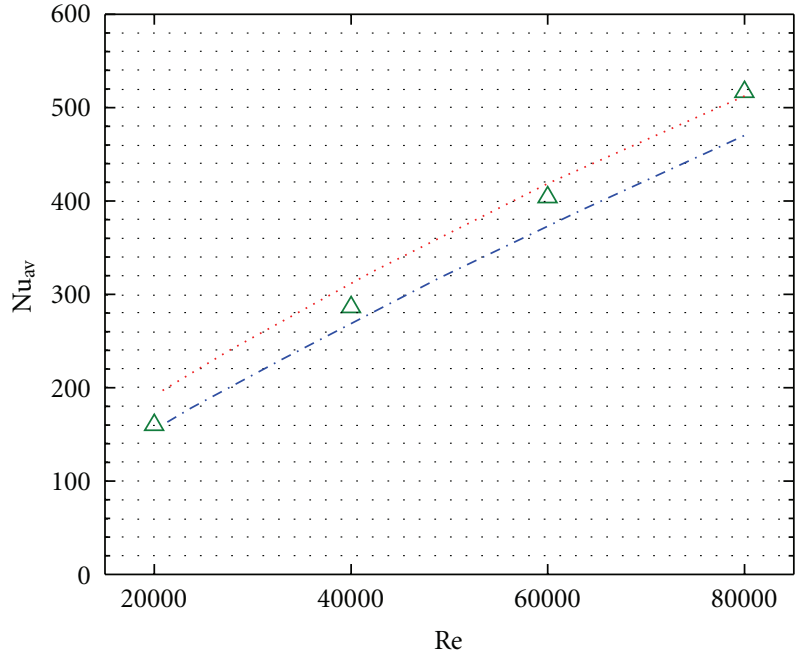

$\mathrm{Al}_{2} \mathrm{O}_{3} /$ water $1 \%$ vol.

-. - Nu (Pak and Cho) [1]

$\mathrm{Nu}$ (Maïga et al.) [9]

$\triangle \mathrm{Nu}$ (ANSYS FLUENT)

(a)

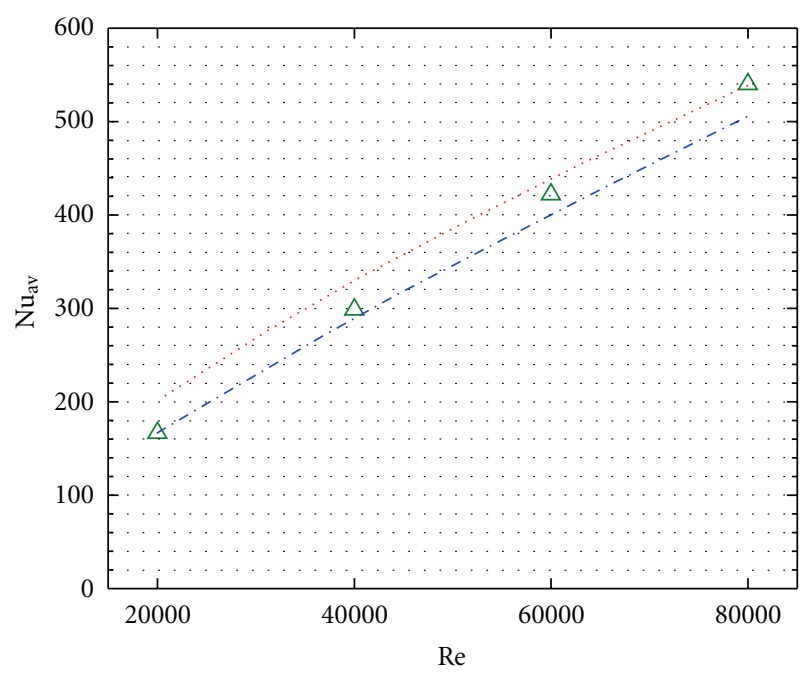

Base fluid 0\% vol.

-. $\mathrm{Nu}$ (Pak and Cho) [1] $\mathrm{Nu}$ (Maïga et al.) [9]

$\triangle \mathrm{Nu}$ (ANSYS FLUENT)

(c)

FIgURE 9: Comparison of average Nu with the correlations.

$q \quad$ Heat flux, $\mathrm{W} / \mathrm{m}^{2}$

Re: Reynolds number

T: $\quad$ Temperature, $\mathrm{K}$

TI: Turbulence intensity

$u_{i}: \quad$ Velocity vector, $\mathrm{m} / \mathrm{s}$

$\dot{u}: \quad$ Root-mean-square of the turbulent velocity fluctuations

$U_{3, b}: \quad$ Axial bulk mean velocity

$x, y, z$ : Coordinates

$U: \quad$ Mean velocity (Re averaged).
Greek Symbols

$\mu$ : Dynamic viscosity, Pa·s

$\rho$ : Density, $\mathrm{kg} / \mathrm{m}^{3}$

$\varphi$ : Nanoparticle volume fraction.

Subscript

av: Average

bf: Base fluid 


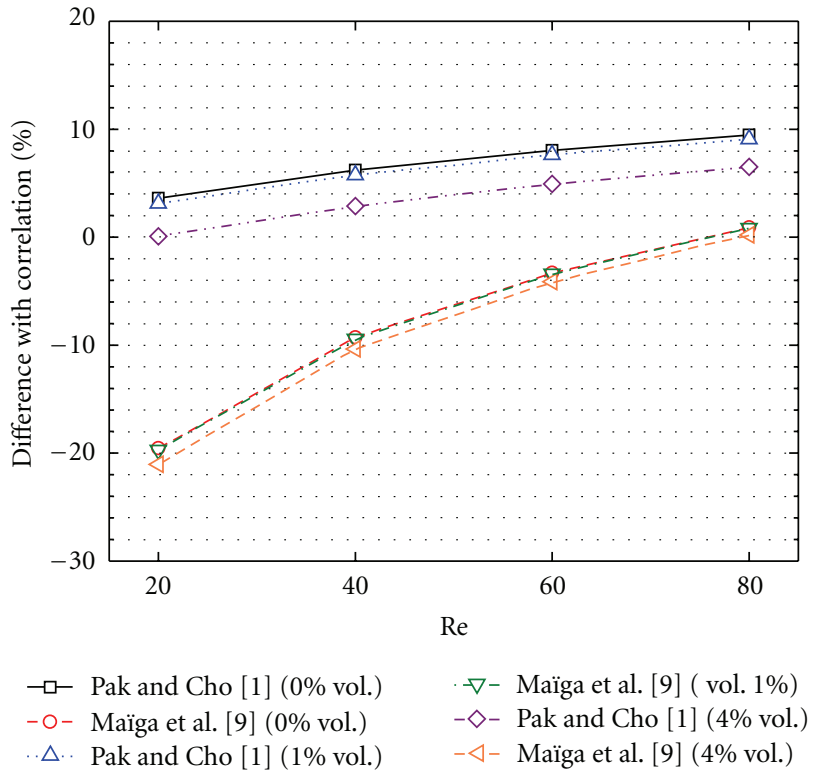

FIGURE 10: Differences of FLUENT result from experimental correlations proposed by Pak and Cho [1] and numerical correlation proposed by Maïga et al. [9].

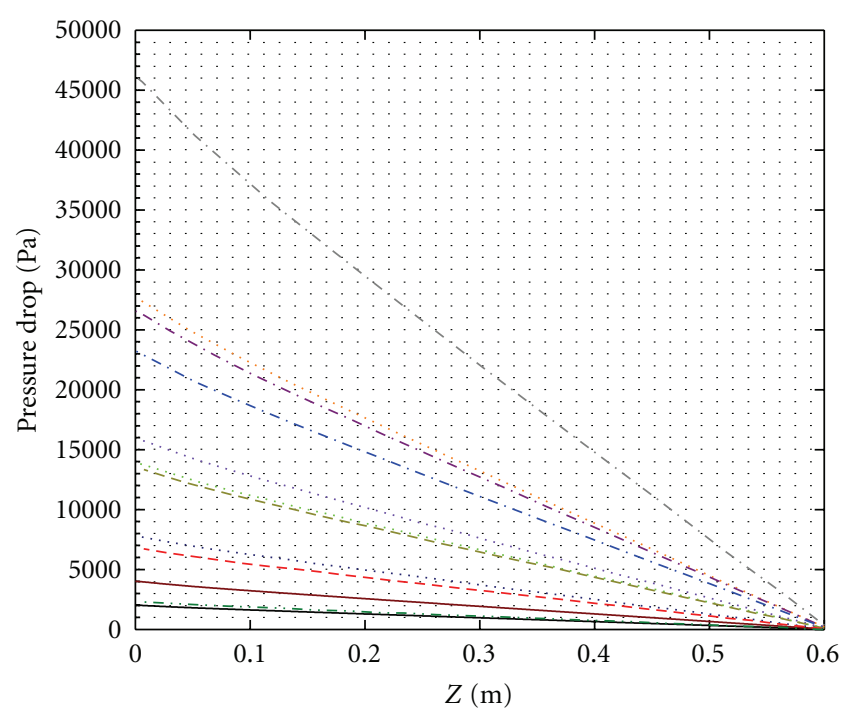

\footnotetext{
- Base fluid $\mathrm{Re}=20000$

- - Base fluid $\mathrm{Re}=40000$

Base fluid $\mathrm{Re}=60000$

. . - Base fluid $\operatorname{Re}=80000$

-.. - Nanofluid $1 \%$ vol. $\mathrm{Re}=20000$

..... Nanofluid $1 \%$ vol. $\mathrm{Re}=40000$

Nanofluid $1 \%$ vol. $\mathrm{Re}=60000$

- . - Nanofluid $1 \%$ vol. $\operatorname{Re}=80000$

- Nanofluid $4 \%$ vol. $\mathrm{Re}=20000$

- - - Nanofluid $4 \%$ vol. $\mathrm{Re}=40000$

Nanofluid $4 \%$ vol. $\operatorname{Re}=60000$

Nanofluid $4 \%$ vol. $\operatorname{Re}=80000$
}

FIGURE 11: Pressure distribution in subchannel for different volume concentration and Re.
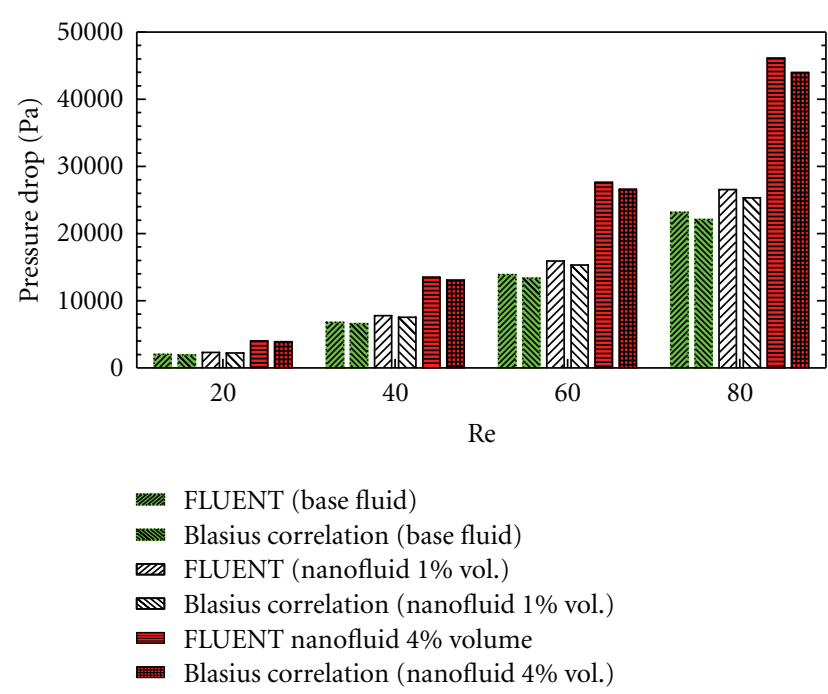

Figure 12: Pressure drop along channel compared with pressure drop estimated by Blasius formula.

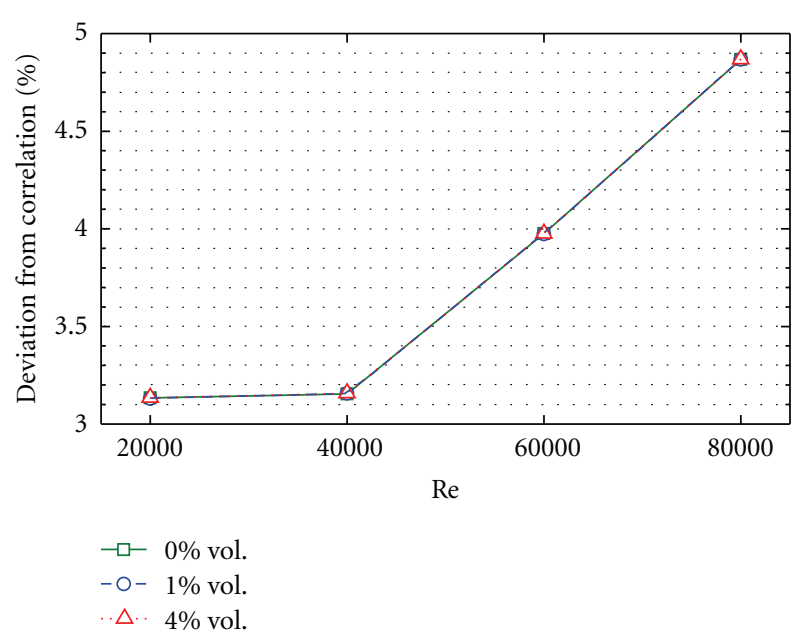

FIGURE 13: Performance of the Blasius correlation for pressure drop.
b: Bulk
$f$ : Fluid
in: Inlet section
nf: Nanofluids
out: Outlet section
p: Particle
$w$ : Wall
0 : Initial value.

\section{References}

[1] B. C. Pak and Y. I. Cho, "Hydrodynamic and heat transfer study of dispersed fluids with submicron metallic oxide particles," Experimental Heat Transfer, vol. 11, no. 2, pp. 151$170,1998$.

[2] Y. Xuan and W. Roetzel, "Conceptions for heat transfer correlation of nanofluids," International Journal of Heat and Mass Transfer, vol. 43, no. 19, pp. 3701-3707, 2000. 
[3] Y. Xuan and Q. Li, "Investigation on convective heat transfer and flow features of nanofluids," Journal of Heat Transfer, vol. 125, no. 1, pp. 151-155, 2003.

[4] J. Buongiorno, "Convective transport in nanofluids," Journal of Heat Transfer, vol. 128, no. 3, pp. 240-250, 2006.

[5] V. Bianco, F. Chiacchio, O. Manca, and S. Nardini, "Numerical investigation of nanofluids forced convection in circular tubes," Applied Thermal Engineering, vol. 29, no. 17-18, pp. 3632-3642, 2009.

[6] V. Bianco, O. Manca, and S. Nardini, "Numerical investigation on nanofluids turbulent convection heat transfer inside a circular tube," International Journal of Thermal Sciences, vol. 50, no. 3, pp. 341-349, 2011.

[7] V. Bianco, O. Manca, and S. Nardini, "Numerical simulation of water/ $\mathrm{Al}_{2} \mathrm{O}_{3}$ nanofluid turbulent convection," Advances in Mechanical Engineering, vol. 2010, Article ID 976254, 10 pages, 2010.

[8] V. Bianco, S. Nardini, and O. Manca, "Enhancement of heat transfer and entropy generation analysis of nanofluids turbulent convection flow in square section tubes," Nanoscale Research Letters, vol. 6, no. 1, pp. 1-12, 2011.

[9] S. E. B. Maïga, C. T. Nguyen, N. Galanis, G. Roy, T. Maré, and M. Coqueux, "Heat transfer enhancement in turbulent tube flow using $\mathrm{Al}_{2} \mathrm{O}_{3}$ nanoparticle suspension," International Journal of Numerical Methods for Heat and Fluid Flow, vol. 16, no. 3, pp. 275-292, 2006.

[10] M. Rostamani, S. F. Hosseinizadeh, M. Gorji, and J. M. Khodadadi, "Numerical study of turbulent forced convection flow of nanofluids in a long horizontal duct considering variable properties," International Communications in Heat and Mass Transfer, vol. 37, no. 10, pp. 1426-1431, 2010.

[11] A. Behzadmehr, M. Saffar-Avval, and N. Galanis, "Prediction of turbulent forced convection of a nanofluid in a tube with uniform heat flux using a two phase approach," International Journal of Heat and Fluid Flow, vol. 28, no. 2, pp. 211-219, 2007.

[12] M. Corcione, M. Cianfrini, and A. Quintino, "Heat transfer of nanofluids in turbulent pipe flow," International Journal of Thermal Sciences, vol. 56, pp. 58-69, 2012.

[13] M. Rahimi-Esbo, A. A. Ranjbar, A. Ramiar, M. Rahgoshay, and A. Arya, "Numerical study of the turbulent forced convection jet flow of nanofluid in a converging duct," Numerical Heat Transfer A, vol. 62, no. 1, pp. 60-79, 2012.

[14] O. Ghaffari, A. Behzadmehr, and H. Ajam, "Turbulent mixed convection of a nanofluid in a horizontal curved tube using a two-phase approach," International Communications in Heat and Mass Transfer, vol. 37, no. 10, pp. 1551-1558, 2010.

[15] M. Massoudi and T. X. Phuoc, "Remarks on constitutive modeling of nanofluids," Advances in Mechanical Engineering, vol. 2012, Article ID 927580, 6 pages, 2012.

[16] R. B. Mansour, N. Galanis, and C. T. Nguyen, "Effect of uncertainties in physical properties on forced convection heat transfer with nanofluids," Applied Thermal Engineering, vol. 27, no. 1, pp. 240-249, 2007.

[17] M. Nazififard, M. R. Nematollahi, K. Jafarpour, and K. Y. Suh, "Augmented safety heat transport in research reactor IR40 using nanofluid," atw-International Journal for Nuclear Power, vol. 57, pp. 262-270, 2012.

[18] M. Nazififard, M. R. Nematollahi, and K. Y. Suh, "Numerical analysis of water-based nanofluid coolant for small modular reactor," in Proceedings of the ASME 2011 Small Modular Reactors Symposium (SMR '11), Washington, DC, USA, September 2011.
[19] M. Nazififard, M. Nematollahi, K. Jafarpur, and K. Y. Suh, "Computational analysis for research reactor IR-40 rod bundle," atw-International Journal for Nuclear Power, vol. 57, no. 8/9, pp. 523-529, 2012

[20] S. J. Palm, G. Roy, and C. T. Nguyen, "Heat transfer enhancement with the use of nanofluids in radial flow cooling systems considering temperature-dependent properties," Applied Thermal Engineering, vol. 26, no. 17-18, pp. 22092218, 2006.

[21] J. A. Eastman, S. R. Phillpot, S. U. S. Choi, and P. Keblinski, "Thermal transport in nanofluids," Annual Review of Materials Research, vol. 34, pp. 219-246, 2004.

[22] S. J. Kim, I. C. Bang, J. Buongiorno, and L. W. Hu, "Surface wettability change during pool boiling of nanofluids and its effect on critical heat flux," International Journal of Heat and Mass Transfer, vol. 50, no. 19-20, pp. 4105-4116, 2007.

[23] J. Buongiorno and B. Truong, "Preliminary study of waterbased nanofluid coolants for PWRs," Transactions of the American Nuclear Society, vol. 92, pp. 383-384, 2005.

[24] J. Buongiorno, L. W. Hu, G. Apostolakis, R. Hannink, T. Lucas, and A. Chupin, "A feasibility assessment of the use of nanofluids to enhance the in-vessel retention capability in light-water reactors," Nuclear Engineering and Design, vol. 239, no. 5, pp. 941-948, 2009.

[25] K. Hadad, A. Hajizadeh, K. Jafarpour, and B. D. Ganapol, "Neutronic study of nanofluids application to VVER-1000," Annals of Nuclear Energy, vol. 37, no. 11, pp. 1447-1455, 2010.

[26] J. Sarkar, "A critical review on convective heat transfer correlations of nanofluids," Renewable and Sustainable Energy Reviews, vol. 15, no. 6, pp. 3271-3277, 2011.

[27] M. R. Nematollahi and M. Nazifi, "Enhancement of heat transfer in a typical pressurized water reactor by different mixing vanes on spacer grids," Energy Conversion and Management, vol. 49, no. 7, pp. 1981-1988, 2008.

[28] ANSYS FLUENT Workbench User's Guide. Release 12.1. ANSYS, Inc., 2009.

[29] C. C. Liu and Y. M. Ferng, "Numerically simulating the thermal-hydraulic characteristics within the fuel rod bundle using CFD methodology," Nuclear Engineering and Design, vol. 240, no. 10, pp. 3078-3086, 2010.

[30] V. Yakhot, S. A. Orszag, S. Thangam, T. B. Gatski, and C. G. Speziale, "Development of turbulence models for shear flows by a double expansion technique," Physics of Fluids A, vol. 4, no. 7, pp. 1510-1520, 1992.

[31] F. W. Dittus and L. M. K. Boelter, "Heat transfer in automobile radiators of the tubular type," University of California Publications of Engineering, vol. 2, pp. 443-461, 1930. 

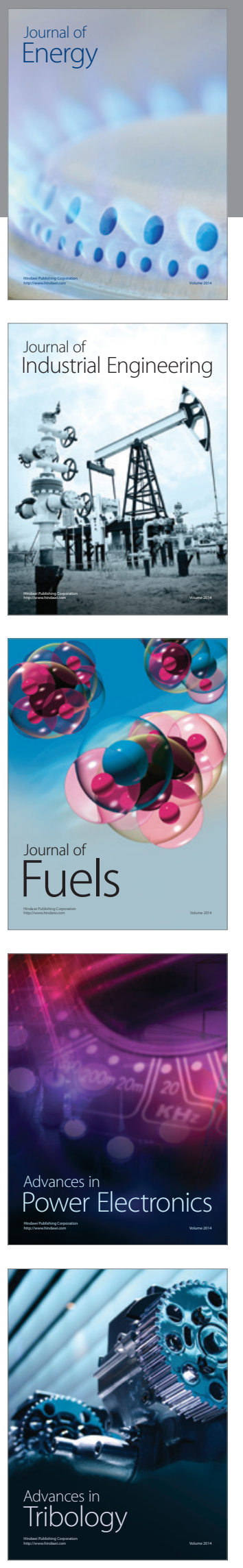
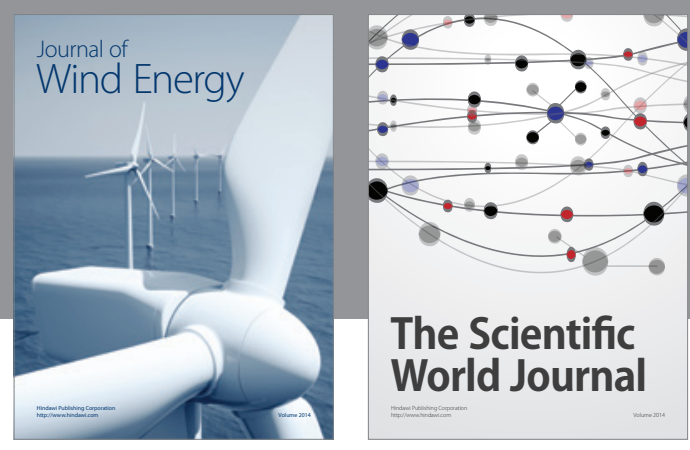

The Scientific World Journal

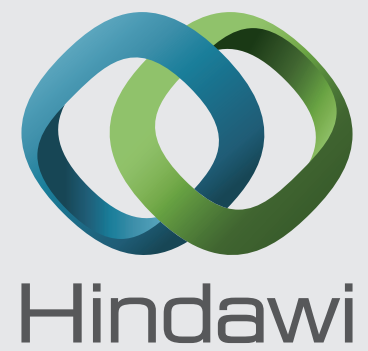

Submit your manuscripts at http://www.hindawi.com
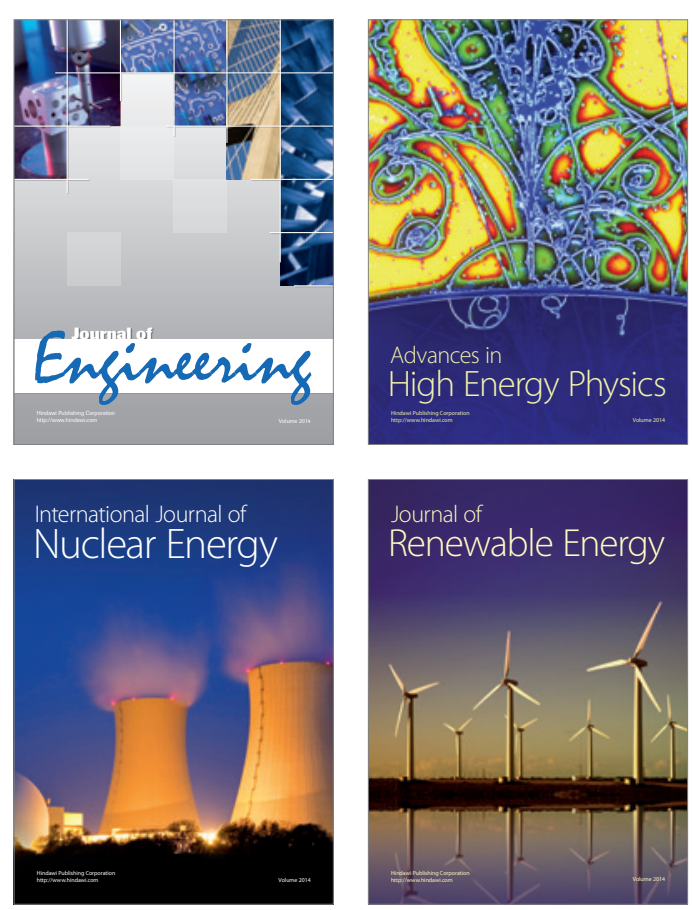

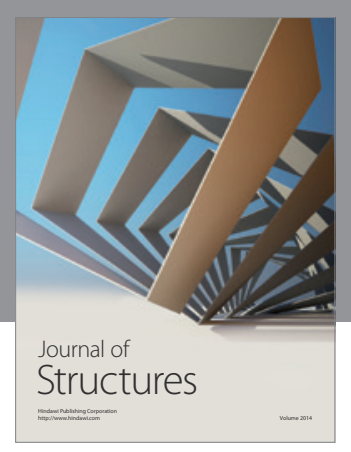

Rotating
Mechinery
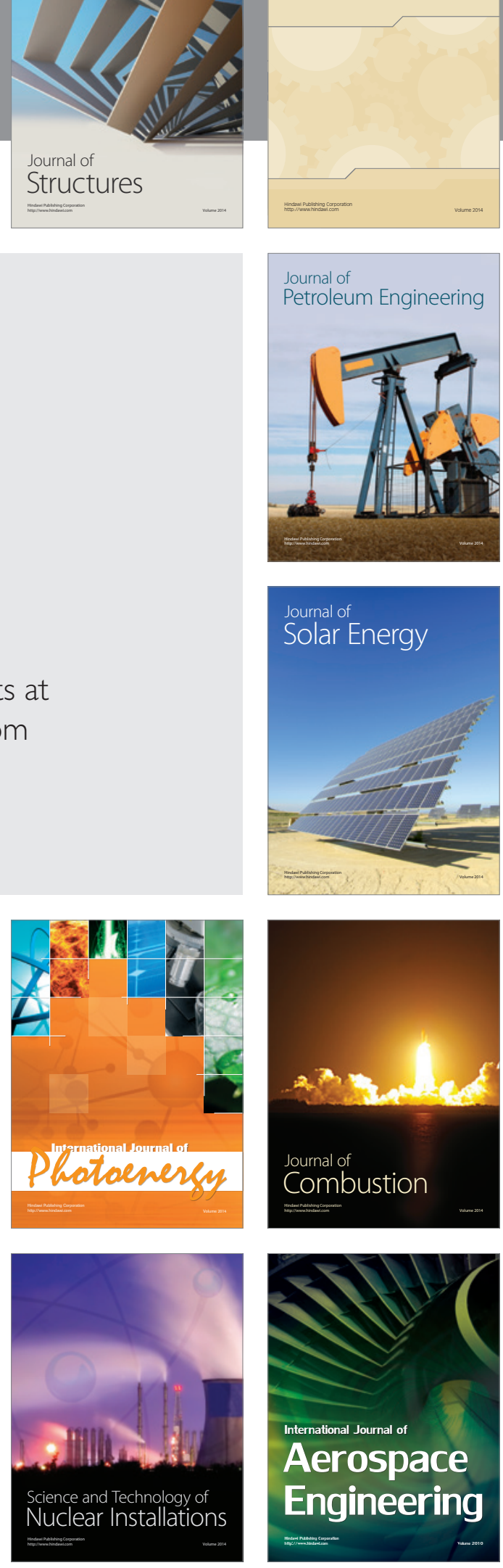